\title{
Inmigrantes sirio-libaneses y sus prácticas económicas (ilegales) en Colombia, 1880-1930*
}

\section{Resumen}

Entre 1880 y 1930, Colombia recibió un número significativo de inmigrantes procedentes de Siria y Líbano, quienes, a través de distintas actividades empresariales, terminaron siendo parte de la élite económica de varias ciudades colombianas. En este artículo estudio ese proceso de consolidación económica, haciendo énfasis en las prácticas económicas ilegales en las que incurrieron algunos de los inmigrantes siriolibaneses que se establecieron en el circuito comercial existente entre la provincia del Sinú, Cartagena y el Atrato. Argumento que actividades como la falsificación de monedas, el contrabando y el acaparamiento de tierras intervinieron en el proceso de acumulación de capital y de consolidación económica que algunos de estos inmigrantes lograron.

Palabras clave: Colombia, sirio-libaneses, contrabando, tierras, prácticas ilícitas.

Referencia para citar este artículo: RHENALS DORIA, Ana Milena (2018). "Inmigrantes sirio-libaneses y sus prácticas económicas (ilegales) en Colombia, 1880-1930”. En Anuario de Historia Regional y de las Fronteras. 23 (1). pp. 49-72.

Fecha de recepción: 27/03/2017

Fecha de aceptación: 24/05/2017

Ana Milena Rhenals Doria: Doctora en historia de América Latina de la Universidad Pablo de Olavide, Sevilla - España. Historiadora de la Universidad de Cartagena, Colombia. Profesora de la Escuela de Historia de la Universidad Industrial de Santander, Colombia. Código ORCID: https://orcid.org/00000003-0341-9635. Correo electrónico: mrhenals@uis.edu.co.

\footnotetext{
*Este artículo está basado en un capítulo de la tesís doctoral: Del ideal europeo a la realidad árabe: Inmigrantes Sirio-Libaneses en el circuito comercial entre Cartagena-Sinú y el Atrato 1880-1930, Universidad Pablo de Olavide, Sevilla-España, 2013.
} 


\title{
Syrian-Lebanese Immigrants and Their (Illegal) Economic Practices in Colombia, 1880-1930
}

\begin{abstract}
Between 1880 and 1930, Colombia received a significant number of immigrants from Syria and Lebanon, who, through various business activities, ended up being part of the economic elite of several Colombian cities. By studying the presence of these immigrants in the commercial circuit of the Caribbean Colombian and the Atrato, I analyze their economic rise, making special emphasis in the intersection between Syrian-Lebanese's economic success and some illegal economic practices. I argue that the money counterfeiting, the smuggling and the land grabbing were crucial in the process of capital accumulation and economic consolidation of some SyrianLebanese immigrants in Colombia.
\end{abstract}

Keywords: Colombia, Syrian-Lebanese, Smuggling, Lands, Illicit Practices.

\section{Imigrantes sírio-libaneses e suas práticas econômicas (ilegais) na Colômbia, 1880-1930}

\section{Resumo}

Entre 1880 e 1930, a Colômbia recebeu um número significativo de imigrantes da Síria e do Líbano, que, através de várias atividades comerciais, acabaram fazendo parte da elite econômica de várias cidades colombianas. Neste artigo, estudo este processo de consolidação econômica, enfatizando as práticas econômicas ilegais nas quais se envolveram alguns dos imigrantes sírio-libaneses, que se estabeleceram no circuito comercial existente entre a província de Sinú, Cartagena e o Atrato. Argumento que atividades como a falsificação de moedas, o contrabando e o monopólio de terras intervieram no processo de acumulação de capital e consolidação econômica que esses imigrantes alcançaram na Colômbia entre 1880 e 1930.

Palavras-chave: Colombia, sírio-libanesa, contrabando, terra, práticas ilícitas. 


\section{Introducción}

"Es sorprendente ver cómo prosperan los turcos en Colombia. Llegan al país con sus maletas llenas de chuchería y en poco tiempo han hecho una fortuna". De esta forma el periódico La Chicharra de Cartagena, en el año de 1911, época en que ya era notable el poder económico que estaban adquiriendo los sirio-libaneses, intentaba explicar su ascendente trayectoria en la vida económica regional y nacional. Según el columnista, no era del todo claro cómo de un día para otro se convertían en comerciantes al por mayor con un enorme capital. En un abierto tono de escepticismo e ironía se preguntaba: “¿de dónde yace el secreto?” Iguales cuestionamientos se originaron dentro de varios habitantes de la provincia del Sinú y el Atrato, donde reiteradamente se plantearon dudas en torno al inusitado éxito económico de los comerciantes siriolibaneses $^{2}$. Las respuestas iban desde quienes explicaban el hecho a partir de su habilidad comercial, pasando por los que hablaban del ahorro, hasta quienes veían en las actividades ilegales la clave secreta de todo este proceso de acumulación de riquezas de los mencionados empresarios.

La historiografía reciente que ha abordado la llegada e inserción de los inmigrantes sirio-libaneses en Colombia ha orientado la discusión hacia el establecimiento de la idea de unos inmigrantes que en corto tiempo logran establecerse de forma sólida en la vida económica de las sociedades donde se ubican, explicando esta realidad solo a partir de sus prácticas austeras y ahorrativas. Según varios de estos estudios, estos inmigrantes, al venir de contextos llenos de dificultades económicas en sus países de origen, habían ejercitado estas prácticas, y sobre todo insistían en la tradición del comercio que traían consigo heredada de los fenicios. Por ejemplo, el escritor Enrique Córdoba, ampliamente citado por quienes han estudiado este tema en la zona del Sinú, señala que los sirio-libaneses llegaron “[...] sin un peso en bolsillo, pero con cinco mil años de ventaja en el arte del comercio. Rápidamente prosperaron y amasaron enormes fortunas"

Aparte de esta caracterización, con la que resaltan el papel que jugaron los siriolibaneses en el Caribe colombiano en el tránsito del siglo XIX al XX, buena parte de estos estudios de plano rechazan, minimizan y en algunos casos, no hacen alusión a la participación de los sirio-libaneses en actividades como el contrabando, el acaparamiento de tierras y la falsificación de monedas. Sin embargo, una revisión más cuidadosa de las fuentes disponibles para la época permite sugerir que algunos de estos inmigrantes se vieron envueltos en estas actividades relacionadas con el contrabando, el acaparamiento ilegal de tierras, la estafa. Este artículo, a partir de la experiencia de los sirio-libaneses que hicieron presencia en el circuito comercial integrado por la Provincia del Sinú, Cartagena y el Atrato, analiza todas estas actividades, y argumenta que estas, junto a sus dinámicas empresariales legales, permitieron que un grupo

\footnotetext{
${ }^{1}$ Archivo Histórico de Cartagena, (A.H.C), La Chicharra, Cartagena, 29 de marzo de 1911.

${ }^{2}$ Biblioteca Nacional de Colombia, (B.N.C), "Por la patria y por la raza", La defensa económica nacional, Cali, 3 de noviembre de 1923.

${ }^{3}$ Córdoba, Enrique. Mi pueblo, el mundo y yo (Bogotá: Ecoe ediciones, 2002).
} 
significativo de sirio-libaneses avanzaran en su proceso de consolidación económica. La existencia de ese conjunto de prácticas revela, además, la fragilidad de un Estado que estaba en pleno proceso de centralización y consolidación nacional.

\section{Sirio-libaneses y su ascenso económico}

Colonizar y poblar los territorios latinoamericanos con inmigrantes -particularmente europeos- fue una de las apuestas defendidas por las elites políticas e intelectuales en el tránsito del siglo XIX al XX. Salvo algunas excepciones (Argentina, Uruguay, Brasil), sin embargo, el grueso de los inmigrantes que llegaron a estos territorios provino de países extra-europeos. La presencia de chinos, árabes y afro-antillanos en varios países de Latinoamérica terminó siendo parte de la realidad social, racial, cultural y económica de los mismos ${ }^{4}$.

En el caso de Colombia, uno de los países que registró uno de los índices más bajos de inmigrantes en el contexto latinoamericano, sirios y libaneses dieron forma a una de sus corrientes inmigratorias más numerosa. Integrados en su mayoría por inmigrantes que buscaron escapar de las persecuciones que el imperio otomano estaba ejerciendo contra los cristianos y por quienes decidieron explorar mejores oportunidades en el marco de una fuerte crisis económica que azotó a Siria y el Líbano, llegaron de manera sistemática a partir de 1880 y lo siguieron haciendo de forma creciente hasta finales de la Segunda Guerra Mundial (1945) .

Estos inmigrantes, que llegaron en un contexto del establecimiento de leyes que los catalogaba como "extranjeros indeseables", iniciaron un progresivo proceso

\footnotetext{
4 Rhenals Doria, Ana Milena y Flórez Bolívar, Francisco Javier. "Escogiendo entre los extranjeros indeseables: afro-antillanos, sirio-libaneses, raza e inmigración en Colombia", en Anuario Colombiano de Historia Social y de la Cultura, vol. XL, núm. 1, 2013, pp. 243-271; Martínez, Frederic. "Apogeo y decadencia del ideal de la inmigración europea en Colombia siglo XIX", en Boletín Cultural y Bibliográfico, vol XXXIV, núm. 44, Banco de la República, Bogotá, 1997; Chávez, Matías Rodrigo y Sourrouille, Marcos. "Redes sociales y territorialidad bolichera de sirios y libaneses en el sudeste de Rio Negro, Argentina (1900-1950)", en Anuario de Historia Regional y de las Fronteras, vol. XXI, núm. 1, enero- julio, 2016, pp. 159-182.

5 Sobre las oleadas inmigratorias árabes: Fawcett, Louise. "libaneses, sirios y palestinos en Colombia”, en Revista Documento, núm. 9, Universidad del Norte, Barranquilla, 1991; Posada Carbó, Eduardo y Fawcett, Louise. "En la tierra de las oportunidades: los sirio-libaneses en Colombia", en Boletín Cultural y Bibliográfico, vol. XXIX, núm. 29, Banco de la República, Bogotá, 1992; Posada Carbó, Eduardo. El Caribe colombiano. Una historia regional 1870-1950 (Bogotá: Banco de la Republica/El Ancora Ed., 1998); Posada Carbó y Fawcett, Louise. "Árabes y judíos en el desarrollo del Caribe colombiano 18501950”, en Boletín. Cultural y Bibliográfico, vol. XXXV, núm. 49, Banco de la Republica, Bogotá, 2000; Viloria De La Hoz, Joaquín. "Lorica una colonia árabe a orillas del río Sinú", en Cuadernos de historia económica y empresarial, núm. 10, Banco de la República, Cartagena, 2003; González Escobar, Luis Fernando. "Sirio-libaneses en el Chocó, cien años de presencia económica y cultural", en Boletín Cultural y Bibliográfico, vol. XXXIV, núm. 44, Banco de la República, Bogotá, 1997; García Estrada, Rodrigo. Los extranjeros en Colombia. Su aporte a la construcción de la Nación 1810-1920 (Bogotá: ed. Planeta, 2006); Vargas, Pilar y Suaza, Luz Marina. Árabes en Colombia. Del rechazo a la integración (Bogotá: ed. Planeta, 2007); Vargas, Pilar. Pequeño equipaje, grandes ilusiones: la migración árabe en Colombia (Bogotá: Taurus ed., 2011).
} 
de inserción a la vida social del país. Como lo ha demostrado la literatura que ha estudiado el tema, durante las últimas décadas del siglo XIX y las primeras del XX estos inmigrantes hicieron de su consolidación económica el elemento central para romper las barreras sociales y los estigmas raciales que sobre ellos pesaban.

Los nombres de Carlos, César, Salomón y Rafael Abuchar, del Libano, y los hermanos Basilio, Camilo, Antonio y Luís Malluk, así como Miguel y Carlos Rumie, Amin y Tufi Meluk, y Moisés Mebarak, de Siria, (algunos de los primeros inmigrantes de este origen en llegar a Cartagena y Barranquilla en la década del 80 del siglo XIX), aparecen una y otra vez protocolizando negocios y conformando sociedades comerciales, hasta el punto de convertirse en una élite económica con inversiones en la navegación fluvial, el comercio, la agricultura y la ganadería ${ }^{6}$.

Entre los años de 1914 y 1923, el transporte y el comercio fluvial en el circuito comercial formado por Cartagena, la rica Provincia del Sinú y el Atrato fue monopolizado por varios inmigrantes de este origen, favoreciéndose de las prerrogativas concedidas por el gobierno departamental de Bolívar, que extendió contratos que garantizaban el libre funcionamiento de sus empresas navieras a lo largo y ancho del río Sinú 7 . Igualmente, los que ingresaban de forma legal al territorio nacional, hicieron uso de las leyes de colonización y ocupación de terrenos baldíos con las que el gobierno colombiano aspiraba a poblar y desarrollar económicamente extensas zonas de la geografía colombiana ${ }^{8}$. Ese proceso de ascenso económico, al tiempo que obedeció a las habilidades comerciales, prácticas de austeridad y redes familiares y de negocios que tejieron los sirio-libaneses resaltadas por la historiografía, en algunos casos, también incorporó el uso de prácticas económicas que rayaban en la ilegalidad.

\section{Falsificación de monedas y alteración de pesas y medidas}

Una de las prácticas por las que recurrentemente fueron acusados y juzgados algunos sirio-libaneses fue la falsificación de moneda. Colombia, durante todo el siglo XIX, vivió un complejo sistema de regulación económico de la moneda que fue desde la libre emisión de metal y papel moneda hasta el monopolio del Estado que estableció un banco nacional. En 1863, durante el periodo liberal, el sistema de banca libre había implicado la posibilidad del libre establecimiento de bancos privados a los que se les autorizaba la emisión de billetes con muy pocas restricciones. Esta ley había favorecido la proliferación de una variedad de bancos regionales sobre los que el

\footnotetext{
${ }^{6}$ Rhenals Doria, Ana Milena y Flórez Bolívar, Francisco Javier. "Distintos sujetos bajo un mismo predicado: Reflexión historiográfica sobre la historia empresarial en el Caribe colombiano", en El taller de la Historia, núm. 1, Revista del Programa de Historia, Universidad de Cartagena, Cartagena, 2009.

7 Rhenals Doria, Ana Milena. "Tejiendo la red: circuitos comerciales, inmigrantes sirio-libaneses y empresarios nacionales en el Caribe colombiano y el Atrato (1880-1930)", en Revista Historia y Espacio, núm. 37, Departamento de Historia, Universidad del Valle, Cali, 2011, pp. 189-212.

${ }^{8}$ Viloria, Joaquín. "Lorica, una colonia árabe a orillas del Río Sinú", en Cuadernos de Historia Económica y Empresarial, núm. 10, Banco de la República (CEER), Cartagena, 2003, p. 32.
} 
Estado tuvo un pobre o casi nulo control y regulación de la política monetaria, lo cual significó la extensión de la especulación financiera y de manejos dudosos ${ }^{9}$.

En 1880, las ideas que defendían el centralismo y el fortalecimiento del control del Estado sobre todo del territorio, comenzaron a tomar fuerza, iniciándose un nuevo régimen que acabaría con el modelo monetario impuesto en 1863. La Ley 39 de 1880 sería la primera muestra firme de ello; con esta Ley se autorizó al gobierno establecer un banco nacional al que se le concedía la emisión exclusiva de billetes, pero esta no fue una transición fácil, pues estuvo marcada por fuertes debates y resistencia por parte de los banqueros privados de las diferentes regiones que vislumbraban con esta decisión su contundente quiebra financiera. La promulgación del Decreto 260 de 1885, en el que se convirtió el billete del Banco Nacional en billete de curso forzoso, generó procedimientos poco legales, porque, aunque el Estado intentaba ejercer su control, no logró que sus billetes tuvieran una amplia circulación nacional ${ }^{10}$.

Precisamente es durante este periodo de transición del sistema monetario colombiano donde los inmigrantes sirio-libaneses comienzan a llegar de forma sistemática al país. Así como lograron articularse a la otra serie de realidades socio-económicas que caracterizaban a Colombia, así mismo supieron sacar provecho de las enunciadas debilidades del régimen monetario. Desde la prensa se afirmaba de forma general el hecho de que algunos miembros de la colonia siria venían incurriendo en el uso y la falsificación de moneda, señalamientos que se dieron mayoritariamente en relación con algunos de los sirios establecidos en Quibdó y Cartagena. Desde finales del siglo XIX varios ciudadanos expresaron su preocupación por este tipo de prácticas que consideraban "perniciosas a la sociedad"11.

$\mathrm{Y}$ durante las tres primeras décadas del siglo $\mathrm{XX}$ estos señalamientos siguieron estando presentes dentro de los comportamientos que los columnistas criticaban sobre el accionar de los mencionados inmigrantes. En el año de 1923, el periódico $A B C$, recogió varios de las críticas que se les adjudicaban a los sirios, destacando que se les acusaba de ser falsificadores consumados: “[...] se acusa a los sirios del Chocó como falsificadores y contrabandistas consumados que, por medios ilícitos, han conseguido fortunas enormes"12.

Pero mucho más contundente que estas alusiones que recaían de manera general sobre los sirio-libaneses, fueron las noticias que trascendieron de los simples

\footnotetext{
${ }_{9}$ Correa, Juan S. "Banca y centralismo en Colombia (1880-1922)", CESA, 2008, http://www.cesa.edu.co/ resourses/library/BORRADORES/banca_y_centralismo_(1880-1922).pdf. (11 de junio de 2013).

${ }_{10}$ Sánchez Torres, Fabio (comp.). Ensayos de historia monetaria y bancaria de Colombia (Bogotá: Tercer Mundo, 1994).

11 B.N.C, El Chocoano, Quibdó, 15 de diciembre de 1898, núm. 1. A.H.C. "Señor administrador de hacienda nacional", El Porvenir, Cartagena, 8 de enero de 1899.

12 B.N.C., "Por la patria y la raza", $A B C$, Quibdó, 15 de noviembre de 1923, p. 1.
} 
señalamientos a procesos judiciales que en algunos casos terminaron en condenas penales. En 1917, el Diario de la Costa de Cartagena referenció el fallo condenatorio contra los comerciantes sirios Feres Aljuri y José Mulki. Luego de precisar que las falsificaciones de monedas y de toda especie de circulantes era constante a lo largo de la geografía nacional, el diario mencionaba que estos inmigrantes, cogidos con los manos en la masa, fueron condenados a 12 años de prisión. Sin embargo, lamentaban que las condenas recaían solo sobre infelices turcos, y no se hacían efectivas cuando se trataban de los grandes empresarios sirios ${ }^{13}$. Dos casos que sirven para ilustrar lo mencionado anteriormente derivan de las denuncias por falsificación de monedas por las cuales enfrentaron largos procesos judiciales los exitosos comerciantes sirios Felix Meluk y Salomón Abuchar. El proceso legal contra Meluk y Abuchar inició en 1899 y se extendió hasta 1909, sustentado en una denuncia por falsificación de billetes del Banco Nacional realizada por el señor Pedro Sierra. La referencia que sobre este caso hace la Gaceta Departamental del Chocó, permite reconstruir los hechos que fueron denunciados por Sierra ante la Jefatura Militar de las Provincias del Chocó, quien en su declaración ante las autoridades afirmó:

En el año 1898, poco más o menos, antes de estallar la guerra ultima, llegué a la casa de almacén del Sr. Salomón Abuchar y tuve la sorpresa de ver grandes cantidades de billetes de a cien pesos $(\$ 100.00)$ expedidos por el Banco Nacional, según se veía en ellos; pero que no eran legítimos, pues estaban unidos en grandes pliegos y uno de los agentes de dicha casa, un joven también sirio, al ver que yo observaba los billetes los escondió y el Sr. Salomón Abuchar salió a atenderme $[\ldots]^{14}$.

Esta declaración se unió a las del reconocido comerciante chocoano Gonzalo Zúñiga, quien dijo que el señor Felix Meluk había puesto en circulación varios billetes falsificados del Banco Nacional; ambas denuncias hicieron abrir investigaciones y juicios que no produjeron ejecutoria, pero que permanecieron abiertos por varios años ${ }^{15}$. Junto a esta práctica de falsificación de billetes, algunos de los sirio-libaneses hicieron circular monedas que no contaban con la autorización del gobierno. El caso que mejor ilustra esta conducta ocurrió en el ingenio Sautatá de propiedad de los hermanos Abuchar y Melluk. Entre 1893 y 1904 esta hacienda, entre solicitudes de adjudicaciones de terrenos baldíos y una compra de la finca Las delicias, tenía una extensión de 10.000 hectáreas. En ella los hermanos Abuchar, junto a sus sobrinos los Meluk, establecieron negocios ganaderos, agrícolas e industriales. Para 1904 esta sociedad tenía 630 cabezas de ganado, 1.500 árboles de cacao, 1.000 de coco, 1.000 de café, 1.000 de caucho, 50.000 matas de plátano y 1.000 árboles frutales; en 1905

\footnotetext{
13 A.H.C., Diario de la Costa, Cartagena, 10 de febrero de 1917, p. 3.

14 B.N.C., "Resolución núm. 12", Gaceta Departamental del Chocó, Quibdó, 15 de abril de 1909, pp. 8586.

15 B.N.C., "Resolución núm. 8", Gaceta Departamental del Chocó, Quibdó, 19 de marzo de 1909, p. 61; "Relación de resoluciones dictadas. Ramo de lo criminal y policía correccional", Gaceta Departamental del Chocó, Quibdó, 14 de enero de 1909.
} 
instalan un aserrío a vapor y un taller de fabricación de muebles. Y finalmente, en 1919, en asocio con inversionistas puertorriqueños, la hacienda termina convirtiéndose en un ingenio azucarero, sembrando 500 hectáreas de Caña para la zafra ${ }^{16}$.

La puesta en funcionamiento de esta variedad de actividades suponía el uso de una gran cantidad de mano de obra, la mayoría oriunda de las riberas del Sinú. Dentro de los cálculos que se establecen este ingenio llegó a poseer 1.000 trabajadores. Precisamente, fue el método de pago de los mencionados obreros lo que llevó a los propietarios del ingenio a incurrir en una serie de irregularidades que originaron bastantes críticas. Amparados en el sistema de comisariato que desarrollaron, obligaban a los trabajadores a recibir su salario en la moneda de única circulación en Sautatá impuesta por ellos, (moneda de aluminio), con la cual debían comprar en los almacenes, restaurantes y pagar los servicios en hospitales y escuelas de propiedad de los dueños del ingenio. La circulación de esta moneda extra-oficial llamó la atención de las autoridades, hecho que fue referenciado por la prensa de la época. Desde el diario $A B C$, en el año de 1921, se establecía que los propietarios del ingenio "[...] habían sido ampliamente criticados y varias veces visitados por las autoridades del gobierno para controlar su cuestionado sistema de comisariato" ${ }^{17}$. Según Marco Cuesta, en su estudio sobre el desarrollo socio-económico del Chocó, la moneda de aluminio, considerada ilegal, fue finalmente prohibida por las autoridades gubernamentales, lo cual sería un elemento que incidió en el declive y cierre del ingenio Sautatá en el año de 1944, cuando la competencia en los precios del azúcar con Cuba se hizo difícil de igualar $^{18}$.

Las autoridades, aparte de estar pendiente de las prácticas de falsificación de monedas o de la circulación extra-oficial de las mismas en las que incurrieron algunos siriolibaneses, también denunciaban las alteraciones que estos inmigrantes hacían de las pesas y medidas, usadas para la venta de los artículos. Una de las denuncias concretas se registró en la ciudad de Cartagena. En el año de 1925, desde el diario La Verdad señalaron que el inspector del barrio Getsemaní comprobó este tipo de comportamientos. Según el diario, el mencionado inspector, al hacer un examen minucioso a los sistemas de pesos y medidas de los comerciantes en general, encontró que un 98 por ciento de los turcos vendían con pesas y medidas incompletas ${ }^{19}$. Es claro entonces que esta fue una práctica utilizada por algunos de los sirio-libaneses en su proceso de acumulación de capital, así como también lo sería el contrabando.

\footnotetext{
16 Ya por fuera del negocio los Meluk, los Abuchar ingresaron al negocio de la destilación de alcohol para comercializar en el Atrato. En el año de 1926 enfrentan algunos inconvenientes económicos y los Meluk vuelven al negocio con un $60 \%$ de las acciones. Sautatá permaneció durante 24 años en el negocio, hasta 1944 que se da el cierre definitivo por la competencia de la azúcar cubana y la crisis económica que afrontó.

17 B.N.C., $A B C$, Quibdó, 2 de octubre de 1921, p. 2.

18 Cuesta, Marco T. El Chocó ayer, hoy y mañana (Bogotá: Colección Fundación, publicaciones consignas, 1986), p. 56

19 A.H.C., "los turcos", La Verdad, Cartagena, 6 de marzo de 1915.
} 


\section{Los sirios y el contrabando}

Desde los tiempos coloniales y a lo largo de todo el siglo XIX y buena parte del $\mathrm{XX}$, producto de la libertad de movimiento de mercancías y gentes de todas las nacionalidades, el contrabando en el Caribe colombiano y el Atrato ha sido una práctica recurrente ${ }^{20}$. El contrabando en Colombia jugó un papel importante en el movimiento económico de las zonas en estudio. La escasa capacidad del gobierno colombiano para establecer su dominio sobre el territorio nacional contribuyó a la extensión de la práctica del contrabando, pues era notable el estado de desprotección de las costas y las zonas de frontera donde se desarrollaba esta actividad ilegal. Cartagena, El Atrato y el Sinú, se constituyeron en zonas dignas de mención en cuanto a la práctica de contrabando, lo que significó que un buen número de habitantes de la Costa Caribe y las provincias, con importantes rutas fluviales, lograran vivir por fuera del control del Estado ${ }^{21}$.

Según Muriel Laurent, entre 1851-1886, la mayoría de los productos introducidos de manera ilícita fueron las mercancías extranjeras, representadas en un $73 \%$ de decomisos. Los textiles eran el renglón más importante dentro de este porcentaje, seguidos de las otras manufacturas para el hogar, alimentos, artículos de lujo y herramientas ${ }^{22}$. Así, negociantes y comerciantes obtenían un mayor beneficio económico a corto plazo, hecho que, sin duda alguna, contribuyó a que nacionales y los extranjeros llegados a estas zonas lograran encontrar con mayor facilidad productos para su comercialización y estos últimos decidieran establecerse en la región para dedicarse a una actividad que era sumamente rentable ${ }^{23}$. Esta práctica comercial ilícita configuró en buena medida los ritmos de vida de los habitantes de estas zonas, no porque esta fuera una condición inherente o cultural sino porque las evidencias históricas demuestran que las autoridades civiles, políticas y militares, al lado de grandes y pequeños comerciantes, practicaban el tráfico ilegal de mercancías en la región y el circuito comercial. Los comerciantes se constituían en el segundo

\footnotetext{
${ }^{20}$ Desde el siglo XVIII el Atrato tenía una reconocida actividad de contrabando, en una Real Cédula expedida por el rey de España en el año 1774 se estableció la conveniencia de "prohibir a los extranjeros la libre navegación y comercio por el Atrato por qué amplio es el contrabando", varios textos hablan de grandes contrabandos y funcionarios comprados en el circuito comercial. Cotes, Eduardo. Diario del alto San Juan y del Atrato, Colección literaria, núm. 35, Fundación Simón y Lola Guberek, Bogotá, 1990. Múnera, Alfonso. "Ilegalidad y frontera 1770-1800", en Meisel, A. (ed.), Historia económica y social del Caribe colombiano, eds. Universidad del Norte- Ecoe, Barranquilla, 1994. Solano, Sergio. Puerto sociedad y conflicto en el Caribe colombiano 1850-1930, Ministerio de Cultura-Observatorio del Caribe colombiano-Universidad de Cartagena, Bogotá, 2003. Velázquez, Rogerio. Fragmentos de historia, etnografía y narraciones del pacifico colombiano negro, Instituto de Patrimonio y Cultura, Bogotá, 2000.

${ }^{21}$ Laurent, Muriel. Contrabando en Colombia en el siglo XIX, prácticas y discursos de resistencia y reproducción, Universidad de los Andes-CESO, Departamento de Historia, Bogotá, 2008, p. 366.

22 Porcentajes de contrabando entre 1851-1886: fraude en las rentas de salinas 24\%, productos de exportación 3\% e introducción ilícita de mercancías extranjeras 73\%, correspondiente a 138 decomisos. Es importante resaltar que la autora señala la existencia de un paralelo importante entre las importaciones legales e ilegales. Ibid.

${ }^{23}$ Desde un artículo publicado en periódico $A B C$ de Quibdó se señalaba la tradición del comercio ilícito, "[...] se recibe el contrabando por el norte del rio Atrato [...], los forasteros acostumbran ir allá a comerciar sus mercancías y sus telas [...]”, B.N.C., $A B C$, Quibdó, 13 de septiembre de 1914.
} 
grupo de responsables de contrabando después de los capitanes de barco. En muchos casos se trataba de comerciantes reconocidos local y regionalmente, como por ejemplo Macía hermanos \& Cía del comercio de Cartagena, o Manuel Madrid y Ezequiel Benedetti ${ }^{24}$. A esto se le sumaba la actitud que la sociedad tenía frente a esta actividad ilícita, pues la misma estaba acompañada de "[...] un alto grado de tolerancia social. Un amplio sector de la población sin discriminación de pertenencia social promovía el negocio ilícito"; y por supuesto esto iba de la mano de sobornos, bajos salarios de los empleados de la aduana, complicidad y corrupción ${ }^{25}$.

El contrabando era tan recurrente que en el año de 1915 un grupo de personas pertenecientes a la banca, el comercio y la industria cartagenera, reconociendo esta realidad de los puertos marítimos y fluviales de la región, exponen como una de las necesidades prioritarias para la fundación de la cámara de comercio de Cartagena, la vigilancia y el control del contrabando realizado por comerciantes entre Cartagena, el Atrato y el Sinú ${ }^{26}$. Es así como el contrabando, actividad que estaba a la orden del día en los circuitos mercantiles ${ }^{27}$ donde participaban activamente los inmigrantes siriolibaneses, también se convirtió en una de las actividades complementarias para obtener riqueza. Desde el periódico El Porvenir de Cartagena, se logran referenciar varios artículos que expresan las quejas por las prácticas de especulación de precios y de contrabando de y hacia Panamá y Cartagena. Aunque en alguno de estos artículos no se hacía mención explícita de los comerciantes sirio-libaneses, la referencia los involucra directamente, ya que para el momento eran los únicos comerciantes extranjeros que se movían constante y regularmente por esta vía; la navegación por los ríos Sinú y Atrato en los primeros años del siglo XX estaba, prácticamente, monopolizada por las casas comerciales de los sirio-libaneses. Desde finales de la década de 1910, entre las embarcaciones que surcaban estas aguas se hallaban los vapores "Sinú" y "Bogotá", de "Chagui hermanos"; el "Bolívar" y el "Cartagena", de "Rumie hermanos"; el "Quibdó", "Sautatá" y "Atrato", de la casa A \& T Meluk; el "Cartagena de Indias" de Salomón Ganem²8.

\footnotetext{
${ }^{24}$ Rhenals Doria, Ana Milena y Flórez, Francisco Javier. "Distintos sujetos bajo un mismo predicado: Reflexión historiográfica sobre la historia empresarial en el Caribe colombiano", en El taller de la Historia, núm. 1, Revista del Programa de Historia, Universidad de Cartagena, Cartagena, 2009, p. 143. Laurent, Muriel, Op Cit., 2008.

${ }^{25}$ Laurent, Muriel, Op Cit., p. 555.

${ }^{26}$ A.H.C., "Bodas de plata de la cámara de comercio", Fígaro, Cartagena, 19 de noviembre de 1940.

${ }^{27}$ Los artículos sobre la temática y la práctica de contrabando permiten ver la importancia que este tenía en las zonas en estudio: A.H.C., Diario de la Costa, "Lo de ayer y lo de hoy", Cartagena, 21 de diciembre de 1916, p. 3; "Goleta apresada", Cartagena, 25 de diciembre de 1916; "Contrabando y contrabandistas", Cartagena, 27 de diciembre de 1916; "Los contrabandos vigilancia de resguardos", El Penitente, Cartagena, 23 de enero de 1910; "Contra el contrabando se piden guardacostas", La Época, Cartagena, 12 de febrero de 1912; B.N.C., "Resolución Na 1 y 16, Quibdó, 15 marzo 1878”, Eco del Atrato, Gaceta Departamental, Quibdó, 10 de septiembre de 1909, p. 169; $A B C$, Quibdó, 10 de junio de 1930, p. 2. "Whisky de contrabando", Quibdó, 13 de agosto de 1927, p. 2; A.H.C., Sección Manuscritos, aduanas, Cartagena, 4 y 20 de marzo de 1905; "Informe de contrabandos", Quibdó, 26 de junio de 1905.

${ }^{28}$ A.H.C., El Porvenir, Cartagena, 17 de octubre de 1902. Otras noticias sobre contrabando en Cartagena: A.H.C., El liberal, Cartagena, 13 de agosto de 1910; El Penitente, Cartagena, 9 de diciembre de 1911; La Época, Cartagena, 21 de junio de 1912; La opinión, Cartagena, 18 de abril de 1926.
} 
Desde finales de siglo XIX las autoridades ya relacionaban la participación de los sirio-libaneses en prácticas de contrabando. En el año 1899, el general Alejandro Restrepo, encargado de inspeccionar las aduanas del país, resaltó dentro de su informe la preocupante realidad que atravesaba la ciudad de Cartagena en términos de la introducción ilegal de mercancías. Al referirse a las irregularidades que se estaban presentando en la mencionada aduana, Restrepo no dudó en señalar que la práctica más común era introducir importantes cantidades de mercancías no por la sección de carga por donde correspondía el pago de impuestos, sino por la sección de equipaje ${ }^{29}$. Y mucho más contundente fue su interés en precisar la nacionalidad de algunos comerciantes que se dedicaban a esta práctica, destacando ante todo a los italianos y los llamados turcos:

Por tanto, suprimí la sección de equipaje, al convencerme de que era una amenaza para el comercio por que los turcos, los italianos y otros comerciantes hacían sus introducciones evadiendo, pudiendo dar sus mercaderías a un precio mucho menor del que podían sostener los importadores por la aduana por el desfalco que se deja demostrado. Para evaluar mejor la importancia de estas irregularidades basta saber, que se me informo que un turco introdujo en una sola ocasión cien (100) baúles de mercancías con las cuales abrió tiendas bien surtidas, donde vende a precios muy inferiores a los corrientes de la plaza. Un comerciante refirió que ese turco al ser interrogado por él, le contestó que la baratura consistía en que el comerciante introducía su mercancía por la machina y él las introducía por la sección de equipajes ${ }^{30}$.

Encaminando la discusión hacia el mismo punto encontramos un artículo publicado en el año de 1915 en el periódico El Espía, en donde se aborda el tema del contrabando en Cartagena; señala que la cantidad de contrabando que se introduce a gran escala al puerto de Cartagena, está siendo introducido tanto por comerciantes de la ciudad como por los turcos que se dedican en su mayoría al comercio de mercancías. Una de las denuncias realizadas en este artículo, implica directamente a un comerciante que, aunque, por motivos legales, no revelan su nombre sí referencian su nacionalidad llamándolo "el turco":

[...] es sabido que muchos turcos pasan contrabandos de artículos, entre esos artículos citaremos los revólveres y las cápsulas. Esos viajes a colón (Panamá) de ciertos hombres y mujeres, es la manera de pasarlos, sépase que esta no es una suposición, es enteramente cierto. Un ejemplo de esto es el turco XX que ha pasado un contrabando de revólveres y cápsulas; va donde los señores Franco Covo \& cía., y les compra unos miles de cápsulas y una docena de revólveres; luego vende esos artículos a menor precio que a quien los compró, es así como se logran muchos su capital $[\ldots]^{31}$.

\footnotetext{
${ }^{29}$ Para la época la oficina de aduana se dividía en dos secciones, la de carga en la que se realizaba todo el proceso de cancelación de impuestos de introducción y la de equipajes que estaba exenta de ellos hasta un número determinado de (2) maletas por pasajero. Al encontrar irregularidades en los procedimientos realizados en esta última el General Restrepo decide suprimirla.
}

${ }^{30}$ B.N.C., El Gladiador, Cartagena, 10 de mayo de 1899, p. 4; Biblioteca Bartolome Calvo (B.B.C), sección de microfilm, "contrabando de los turcos", El Porvenir, Cartagena, 12 de febrero de 1899.

${ }^{31}$ A.H.C., El espía, Cartagena, 20 de febrero de 1915. 
Junto a este tipo de informes, noticias y denuncias que de manera general se referían a los turcos, como contrabandistas, también es posible referenciar diversos artículos de prensa que ahora si de manera específica denunciaron la participación en prácticas de contrabando de los inmigrantes sirio-libaneses que actuaban en el circuito comercial existente entre Cartagena y los ríos Atrato y Sinú. Las compañías comerciales A. \&. T Meluk y "Abuchar Hermanos", que tenían casas comerciales establecidas en Cartagena y el Chocó, se vieron involucrados en denuncias sobre contrabando que recibían y enviaban hacia Panamá, o el envío de mercaderías supuestamente de Cartagena al Sinú que realmente iban a parar al $\mathrm{Atrato}^{32}$. Desde la prensa chocoana también se señalaba que los señores Abuchar y varios de los sirios establecidos en esta intendencia se dedicaban al contrabando ${ }^{33}$.

Una preocupación similar por este alarmante contrabando fue registrada por varios periódicos de Cereté. En el año de 1918, desde el diario La Voz del Sinú, señalaban que esta práctica era realizada por los empresarios nacionales y extranjeros, y era un hecho recurrente dentro de los círculos comerciales de la región: "[...] en todos los puertos de nuestra Costa y en todas las fronteras, se hace el contrabando a gran escala, no solo por ladrones de baja estofa, sino principalmente por titulados caballeros de alta sociedad y por inmigrantes dedicados al comercio, y lo practican las más veces a la sombra de venales autoridades, que les ayudan para repartirse las ganancias" ${ }^{34}$.

Algunos de los inmigrantes sirio-libaneses que se radicaron en Cereté no escaparon a esta dinámica. Los hermanos Chagui, por ejemplo, propietarios de una de las casas comerciales más importantes de esta plaza, estuvieron inmersos en esta práctica. En diversos artículos de la prensa local se reseñaron los acontecimientos que dan cuenta de las prácticas ilícitas en las que venían incurriendo los Chagui. Desde el periódico El Rayo, en el año de 1910, el alcalde del distrito de Cereté explicaba los motivos por los cuales los señores Chagui habían sido reducidos a prisión. Según el funcionario, estos inmigrantes sirios “[...] venían desde hacía algún tiempo introduciendo café de contrabando con perjuicio del distrito y del comercio en general" ${ }^{35}$. Las constantes denuncias realizadas por comerciantes locales que no podían competir con los bajos precios ofrecidos por los Chagui, pues estos evadían el pago de los derechos de importación, obligó al alcalde a establecer un impuesto que contemplaba "una multa igual al cuádruplo del impuesto a los que se les sorprendiera café de contrabando"36; disposiciones que fueron trasgredidas por los Chagui:

\footnotetext{
${ }^{32}$ González, Luis F. "Sirio-libaneses en el Chocó, cien años de presencia económica y cultural”, en Boletín Cultural y Bibliográfico, vol. XXXIV, núm. 44, Banco de la República, Bogotá, 1997, p. 77.

${ }^{33}$ B. N.C., "Por la patria y por la raza", artículo publicado en un periódico caleño y citado en $A B C$. Quibdó, 15 de noviembre de 1923.

${ }^{34}$ Centro de Documentación del Banco de la Republica Montería (C.D.B.R.M), "Contrabando", Voz del Sinú, Cereté, 7 de noviembre de 1918.

35 C.D.B.R.M. El Rayo, Cereté, 29 de diciembre de 1910. p. 3

${ }^{36}$ C.D.B.R.M. El Rayo, Cereté, 29 de diciembre de 1910. pp. 3 y 4
} 
[...] pasados algunos días fueron los señores Chagui sorprendidos con veinte sacos de café de contrabando. Comprobado el incidente les notifico una multa de 40 (pesos), dos pesos por cada saco, llegados a mi oficina los Hnos. Chagui se negaban al pago [...] fue entonces cuando los hice arrestar en la cárcel pública $[\ldots]^{37}$.

Era evidente que el contrabando estaba dentro de las dinámicas mercantiles adelantadas por algunos de los inmigrantes sirio-libaneses. Además de evadir el pago de los derechos de importación, recibían mercancías a muy bajos costos que garantizaban la redistribución de forma rápida de las mismas, obteniendo unos márgenes de ganancia que junto con las otras actividades les permitió asegurar una estabilidad económica con la cual lograron tener un fuerte impacto al interior de los diversos ámbitos de las sociedades en estudio. Contrario a lo sugerido por la historiografía que ha abordado esta temática, interesada en mostrar solo la imagen de unos siriolibaneses "trabajadores, austeros y honestos", restándole importancia a los casos de contrabando en los que se vieron involucrados ${ }^{38}$, lo anteriormente anotado demuestra que la práctica del contrabando no estuvo tan aislada de las actividades económicas a las que algunos de estos inmigrantes se dedicaron, como tampoco lo estuvieron del acaparamiento ilegal de tierras.

\section{Acaparamiento de tierras}

Una de las medidas implementadas por el gobierno colombiano para avanzar en el desarrollo económico del país y, sobre todo, para promover la inmigración fue la colonización de los terrenos considerados como baldíos por la nación. Según el Estado estos eran aquellos terrenos incultos, pertenecientes a la nación, propios para la explotación agrícola y/o ganadera, que serían adjudicados a nacionales y extranjeros, por lo que todo el territorio nacional se vio congestionado con demandas de titulación y apropiación de terrenos y globos baldíos, tanto por parte de grandes empresarios como por pequeños colonos ${ }^{39}$. Las medidas de adjudicación se vieron reflejadas en las esferas provinciales y distritales. Desde mediados de siglo XIX fueron varios los intentos de las autoridades de la provincia de Cartagena por promover la prosperidad en territorios del Sinú a través de la aprobación de leyes relacionadas con la adjudicación de terrenos. En diversas ocasiones, por ejemplo, la cámara provincial de Cartagena, apoyada por hacendados y comerciantes de la provincia, expresó, tanto para individuos nacionales como para inmigrantes extranjeros, la necesidad de una mano de obra especializada para estimular y fomentar empresas de desarrollo en áreas de territorios fértiles.

\footnotetext{
${ }^{37}$ C. D. B. R. M, El Rayo, Cereté, 29 de diciembre de 1910, pp. 5.

${ }^{38}$ Viloria, Joaquín. "Lorica, una colonia árabe a orillas del Río Sinú”, en Cuadernos de Historia Económica y Empresarial, núm. 10, Banco de la República (CEER), Cartagena, 2003, p. 32.

${ }^{39}$ Le Grand, Catherine. Colonización y protesta campesina de Colombia 1830-1950 (Bogotá: Universidad Nacional de Colombia, 1998).
} 
Para el cumplimiento de estas aspiraciones, se decretaron varias ordenanzas en la cámara para reglamentar las distintas formas de adquirir y acumular riquezas en el Sinú. La ordenanza del año de 1842 del 21 de septiembre estimulaba la inmigración de los extranjeros industriosos para promover adelantos en la agricultura; se auxiliaban con la suma de cinco mil pesos a las empresas y con veinte pesos cada inmigrado, siempre y cuando fuesen más de diez. En el mismo sentido, la ordenanza expedida el 17 de octubre de 1848 autorizaba que quien necesitara tierras para algún establecimiento rural o pecuario por un lapso de diez años, las solicitara por escrito para que le fueran adjudicadas ${ }^{40}$.

Este mismo espíritu del gobierno nacional por promover el acceso a los territorios baldíos se vio en los años finales del siglo XIX y los primeros del XX. En el año de 1874, el Estado, a través de la Ley 61 del 24 de junio, estableció que:

[...] todo individuo que ocupe terrenos de la clase Baldíos adquiere derecho de propiedad en la tierra que cultiva, cualquiera que sea su extensión. El artículo 20 de esta Ley señalaba que, si se establecían la cría de ganado o la siembra de cacao, café, caña de azúcar u otra clase de cultivo permanente, el colono adquiría la propiedad y tenía derecho a que se le adjudicara gratuitamente una porción de terreno adyacente igual en extensiones a la parte cultivada ${ }^{41}$.

En el año de 1882, la Ley 48 mantuvo el principio de adquirir propiedad por cultivo; el procurador general, Clímaco Calderón, intentando explicar el alcance de esta Ley en el año de 1883 , no solo señalaba en que no existía ninguna distinción entre nacionales y extranjeros, sino que indicaba que los últimos no necesitaban cartas de naturalización para acceder a los terrenos ${ }^{42}$. En 1906, el Decreto 23 propició el fomento de la agricultura de cacao y caucho en terrenos baldíos de la nación concediendo una prima consistente en una adjudicación definitiva, hecha por el Ministerio de Obras Públicas y Fomento, de mil hectáreas de terrenos baldíos donde tuvieran los cultivos ${ }^{43}$.

Dada las enormes cantidades de zonas baldías y las riquezas naturales de los territorios del Caribe colombiano, las autoridades en la primera mitad del siglo XX insistieron en la necesidad de impulsar y fomentar la colonización de las tierras baldías en el departamento de Bolívar. Así se desprende de una comunicación enviada por el Ministerio de Agricultura y Comercio al gobernador de Bolívar en el año de 1917, en la que le expresaban que era necesaria la "[...] explotación de todas las riquezas naturales $[\ldots]$ la nación adjudicara día por día muchos centenares de tierras baldías a peticionarios de todas las nacionalidades"44. Según Hermes Tovar, en su análisis sobre las tierras baldías en el siglo XIX, el departamento de Bolívar, desde este siglo, vivió

\footnotetext{
${ }^{40}$ Abad, Gustavo. "Cereté su historia y cultura", Cereté, 1997, p. 75.

${ }^{41}$ Lopera, Jaime. "La colonización del Quindío", capitulo X: la fundación de Armenia, http://www.calarca. net/libro/index10.html 2010, (20 de agosto de 2013).

${ }^{42}$ Archivo General de la Nación, (A.G.N.), Baldíos, tomo 4, Bogotá, 7 de mayo de 1883, pp. 221-258.

${ }^{43}$ Lopera, Jaime, Op Cit.

${ }^{44}$ A.H.C, "Interesante comunicación del ministerio de agricultura y comercio", Gaceta Departamental, Cartagena, 14 de diciembre de 1917, núm. 2241.
} 
una intensa demanda de tierras por parte de empresarios nacionales y extranjeros ${ }^{45}$. Para el caso del Atrato la política no fue distinta, y sobre este particular se dictaron leyes de inmigración y baldíos, y discursos que fomentaban la colonización del Chocó. En el año 1871 el gobierno nacional de los Estados Unidos de Colombia estableció una Ley de protección de los inmigrantes extranjeros y de fomento de tierras baldías, que les permitía obtener la adjudicación de hasta 25 hectáreas de tierras baldías, y a quienes se establecieran en la costa norte del pacifico gozarían de las mismas garantías que se otorgan a los nacionales para la introducción de mercancías, ranchos, etc. Para lograr este objetivo el gobierno nacional cedió, en esta zona, 100.000 hectáreas baldías para el fomento de la inmigración, ordenando se facilitaran los procesos de adjudicación de minas y tierras a favor de los extranjeros ${ }^{46}$.

Sumado a esto se dio el establecimiento de decretos en 1898 que daban como prima a los cultivadores de cada 20.000 árboles del caucho o cacao la cantidad de 1.000 hectáreas de terrenos baldíos en esta zona, y leyes que prohibían el recaudo del impuesto predial a cultivadores y colonos de terrenos baldíos, por ser este un perjuicio enorme a la colonización de regiones inhabitadas como Quibdó ${ }^{47}$, hechos que se convirtieron en grandes atractivos para quienes estaban en busca de establecer negocios. En el mismo sentido se crearon una serie de incentivos económicos que buscaban promover los cultivos en los terrenos baldíos de la Intendencia del Chocó. En efecto, en el año de 1907 el intendente dictó un decreto asignando una prima de 1.000 pesos oro a cada persona o compañía que presentara una nueva plantación de caucho que contuviera mínimo 25.000 árboles $^{48}$. De manera que la solicitud y adjudicación de terrenos baldíos al finalizar el siglo XIX y durante el siglo XX fue una práctica sistemática en las provincias del Atrato y Sinú. Nacionales e inmigrantes aparecen referenciados, tanto en los protocolos notariales como en los registros del Departamento de Baldíos del Ministerio de Obras Públicas, realizando esta actividad de forma legal.

Los empresarios nacionales que estaban presentes en el circuito comercial entre Cartagena, la provincia del Sinú y el Atrato solicitaron la adjudicación de los títulos de propiedad sobre terrenos baldíos. En 1896, por ejemplo, José Pablo Ágil, habitante del Chocó, solicitó le fueran adjudicadas 920 hectáreas de tierras baldías en Quibdó. Siete años más tarde, en Cereté, los señores Lázaro García y Francisco Movilla solicitaron a la gobernación del departamento de Bolívar la adjudicación de 4800 fanegas de tierra ubicadas en el corregimiento de san Carlos para su cultivo. Luego de un largo proceso de revisión por parte de las autoridades eran entregados los títulos de propiedad, como

\footnotetext{
${ }^{45}$ Tovar, Hermes. "Los baldíos y el problema agrario en la costa Caribe de Colombia (1830-1900)", en Revista Fronteras, núm. 1, Centro de Investigaciones de historia colonial, Instituto de Cultura Hispánica, Bogotá, 1997, pp. 35-45.

${ }^{46}$ B.N.C., Estados Unidos de Colombia, Lei sobre protección de los inmigrantes extranjeros y lei de fomento de tierras baldías, Imprenta Mercado avas, 1871, Bogotá. Ley 63 de 11 de junio de 1871, Capítulo V, Artículo 41.

47 A.G.N., "Decretos", Baldíos, tomos 33 y 41, Cartagena, septiembre 5 de 1910, Quibdó, julio 31 de 1917, pp. 392 y 175 .

${ }^{48}$ B.N.C., "Por los agricultores", El Chocó, Quibdó, 16 de noviembre de 1907.
} 
ocurrió en el año de 1903, cuando la compañía Monroy Londoño, asentada en Quibdó, recibió 96 hectáreas de tierras ${ }^{49}$.

Los inmigrantes sirio-libaneses también acudieron a los trámites legales para acceder a estos beneficios. Desde finales del siglo XIX algunos de ellos comenzaron a cultivar tierras baldías para posteriormente solicitarlas en adjudicación como cultivadores, como lo establecía la ley. Un ejemplo significativo es el de Tufik Meluk, quien, junto a Salomón Abuchar, desde 1899 empezó a civilizar 2.550 hectáreas de tierras ubicadas en las inmediaciones de Quibdó, terrenos que solicitó en adjudicación en 1906 y $1914^{50}$. O lo ocurrido con los inmigrantes sirios Carlos y Salomón Nader, quienes solicitaron doscientas cincuenta fanegas de tierras en el Sinú para su explotación, las cuales le fueron adjudicadas ${ }^{51}$. También el caso de Amín Melluk, propietario de la sociedad comercial A \& T Melluk establecida en Cartagena, a quien el Ministerio de Agricultura en el año de 1920 le adjudica -a nombre de su compañía comercial- un globo de tierras baldías ubicado en la costa occidental del golfo de Morrosquillo, con una extensión superficiaria de 2.531 hectáreas a orilla del océano en una extensión de mil (1000) metros ${ }^{52}$.

Pero no siempre el acceso de estos territorios se dio dentro del marco de lo legal. El acaparamiento indebido de tierras fue una práctica recurrente por algunos de los habitantes del Caribe colombiano y el Atrato. Las quejas por adjudicación de denuncias de terrenos baldíos, que no lo eran en realidad, eran numerosas, por lo que el historiador Hermes Tovar afirma que "[...] los baldíos fueron escenarios de conflicto entre poseedores históricos y quienes llegaban amparados por las nuevas leyes que entregaban tierras" ${ }^{\prime 5}$. En repetidas ocasiones, ciudadanos de Cartagena y Chocó manifestaron de manera general las irregularidades que se estaban presentando con la adjudicación de terrenos baldíos. En el caso de Chocó le insistían al Ministerio de Industria que era grave que el gobierno adjudicara baldíos a tantos ciudadanos extranjeros que "[...] alegando títulos de cultivadores, no adquiridos, pretenden hacerse dueños de riquísimos terrenos" ${ }{ }^{4}$, mientras que desde Cartagena, aunque reconocían la importancia de la colonización de los territorios baldíos, advertían la necesidad de adjudicarlos atendiendo a los mecanismos establecidos por la ley y con ello evitar el acaparamiento indebido. En el año de 1913, desde el periódico La Época, describieron esa preocupación en los siguientes términos:

\footnotetext{
${ }^{49}$ A.G.N., "Baldíos", tomo 16, Quibdó, 19 de septiembre de 1896, p. 73. Tomo 20, Quibdó, 29 de septiembre de 1903, p. 51.

${ }^{50}$ A.G.N., "Baldíos", tomo 25, Quibdó, 9 de mayo de 1906, p. 162. B.N.C., "Aviso el intendente nacional del Chocó”, Gaceta de la Intendencia, Quibdó, 19 de enero de 1914, p. 916.

${ }^{51}$ A.H.C., "Denuncio de tierras Baldías", en Registro de Bolívar, Cartagena, 8 de octubre de 1904/“Baldíos", Cartagena, 24 de octubre de 1908.

52 A.H.C., Notaria primera, caja 263, tomo 10, escritura pública núm. 752, Cartagena, 15 de diciembre de 1920.

${ }^{53}$ Tovar, Hermes. "Los baldíos y el problema agrario en la costa Caribe de Colombia (1830-1900)", en Revista Fronteras, núm. 1, Centro de Investigaciones de historia colonial, Instituto de Cultura Hispánica, Bogotá, 1997, p. 36.

54 A.G.N. "Baldíos", Tomo 33, Quibdó, octubre 6 de 1924, p. 10
} 
No podría desconocerse que la colonización de nuestras tierras incultas y lejanas es una de las necesidades más apremiantes y el mejor medio de asegurar nuestra soberanía. [...] pero no creemos que el medio de civilizar nuestras regiones apartadas, sea atropellar intereses ya creados y prescindir de la legislación vigente. La Cámara debe estar encaminada a velar por la conveniente adjudicación de baldíos en regiones de excepcional importancia para el país, expuesta hoy más que nunca a la rapacidad extranjera ${ }^{55}$.

En Quibdó se señalaba recurrentemente la adjudicación de terrenos de posesión de comunidades indígenas como baldíos, y la invasión de cultivadores que con sus labranzas y siembras acaparaban de forma ilegal las posesiones de los antiguos resguardos. Este es el caso de la queja que se establece ante el Ministerio Público por la adjudicación de terrenos indígenas que se hizo en el año de 1920 en contra de la señora Fulgencia Cossio, quien supuestamente estaba acaparando varios terrenos que en realidad eran posesión de una comunidad indígena ${ }^{56}$.

Algunos de los sirio-libaneses que se establecieron en los tres puntos en estudio no fueron ajenos a esta realidad. Una de las primeras formas de acaparamiento utilizada por los mencionados inmigrantes fue extender sus propiedades a partir del encerramiento de los territorios cercanos a las ciénagas. Según lo establecido por Orlando Fals Borda, uno de los investigadores que más ha estudiado los conflictos en torno a la posesión y acumulación de tierras en la zona del Sinú, el inmigrante sirio Miguel Calume estuvo inmerso en esta actividad. Fals señala que Calume acumuló por lo menos 1.200 hectáreas de tierra, producto del acaparamiento de tierras baldías y de terrenos aledaños a las ciénagas, que eran destinados a la agricultura y la ganadería $^{57}$. En la provincia del Sinú, además de Calume, estaban Ángel Manzur y Barbara Issac, quienes fueron denunciados por acaparar y cercar grandes extensiones de terrenos. En la denuncia se establecía el reclamo formal por los abusos contra los colonos cometidos por los mencionados sirios, ya que "[...] estos se han usurpado gran cantidad de terrenos, montes, playones, ciénagas, aluviones y palmares, que cercaron con alambre; puntos que estaban dedicados a pastos naturales dedicados a la ganadería unos y otros a la agricultura" 58 . Este hecho condujo a que un grupo de 40 ciudadanos elevaran una queja al Ministerio de Industria, donde se declaraban directamente afectados por el acaparamiento ilegal, y exigían que se ampararan los

\footnotetext{
55 A.H.C. "El problema de los baldíos", La Época, Cartagena, octubre 16 y noviembre 8 de 1913.

56 A.G.N., "Baldíos", Tomo 47, Quibdó, 2 de marzo de 1920, p. 10.

${ }^{57}$ Fals Borda, Orlando. Historia Doble de la Costa, tomo IV (Bogotá: Ancora Editores, 2000), pp. 157A. Investigaciones que han abordado un periodo de estudio más reciente permiten visualizar la continuidad de estos acaparamientos de tierras por parte de los inmigrantes sirios en el Sinú. "Estos inmigrantes han utilizado el poder político para implementar acciones ilícitas sobre la tierra, especialmente sobre tierras de ciénagas. William Salleg, por ejemplo, aparece con títulos de propiedad sobre una gran porción de la ciénaga de la Martinica, y por esto ha estado en continuo enfrentamiento con los campesinos sin tierra de la zona que reclaman esas tierras del estado para trabajar. Otro tanto le sucede a Lawandio Barguil que extiende voluntariosamente sus linderos y cercados sobre la ciénaga grande. Por su parte, Elias Milane, el mayor terrateniente en el cultivo de algodón en Córdoba, ha confrontado levantamientos campesinos por extender sus linderos sobre la ciénaga grande". Alzate, Alberto y Brunal, Berta. Tenencia y Concentración de la tierra en Córdoba (Montería: ed. Fundación del Caribe, 1982), p. 23.

58 A.G.N., "Baldíos", Tomo 75, Montería, 30 de enero de 1930, p. 148.
} 
derechos de los agricultores y colonos nacionales frente el abuso de los inmigrantes sirio-libaneses ${ }^{59}$.

Otro comportamiento ilegal realizado por algunos de los inmigrantes sirio-libaneses frente al uso de los terrenos baldíos fue la utilización de los mismos como garantías para cubrir préstamos e hipotecas sin contar con los títulos de propiedad. El código fiscal tajantemente prohibía la realización de ventas e hipotecas sobre terrenos baldíos, antes de su adjudicación definitiva ${ }^{60}$, pero algunos empresarios de este origen pasaban por alto esta regulación. Por ejemplo, en el año de 1925, el sirio Checry Fayad, establecido en Lorica, había tomado posesión de unos terrenos baldíos que se hallaban dentro de la jurisdicción del distrito en mención. Estos terrenos que, para este mismo año, estaba solicitando al gobierno nacional a título de cultivador, los utilizó como garantía de pago de un crédito hipotecario que realizó a la casa comercial Rafael del Castillo por la suma de veintisiete mil trescientos setenta y cinco pesos $(\$ 27.375)^{61}$.

Junto al acaparamiento de terrenos cercanos a las ciénagas y la utilización de los baldíos como garantía sin poseer los títulos adjudicados por el gobierno, una de las estrategias más frecuentes utilizadas por ciertos sirio-libaneses fue denunciar territorios baldíos como zonas de minas. Generalmente, los procesos de adjudicación de baldíos tardaban más de cinco años, pues requería que quienes lo pretendían demostraran que habían civilizado los terrenos y desarrollado en ellos cultivos o actividades agrícolas, mientras que la adjudicación de minas solo requería denunciarla ante la autoridad competente y no tardaba tanto ${ }^{62}$. Dada su riqueza aurífera y minera, este tipo de prácticas fue muy común en la Intendencia del Chocó, lo cual obligó a las autoridades a suspender, en el año de 1904, toda adjudicación de minas y tierras baldías a favor de individuos, entidades o compañías extranjeras en el territorio chocoano. A partir de este momento se inició una revisión a los códigos y leyes sobre minas y tierras baldías, siendo significativa la reforma que introdujo el Ministerio de Obras Públicas, en el año de 1905, cuando en el Artículo 11 de los Decretos de baldíos estableció que ninguna adjudicación de tierras podría tener una extensión superior a mil hectáreas ${ }^{63}$.

Las transgresiones a estas regulaciones al parecer eran frecuentes en el Chocó, pues en varias oportunidades los órganos de prensa oficiales recogieron las denuncias de las autoridades, que subrayaron los abusos que se cometían casi siempre contra los pequeños cultivadores. En 1909, desde Istmina, distrito del Chocó, le informaban al departamento de baldíos del Ministerio de Fomento que "[...] concesiones mineras en ríos navegables del Chocó con autorización traspasarlas a extranjeros entrañan

\footnotetext{
${ }^{59}$ Ibid.

${ }^{60}$ Artículo 60 del Código Fiscal, 1919. A.H.C., El Porvenir, Cartagena, 3 de octubre de 1921.

${ }^{61}$ A.H.C., notaria primera, escritura pública núm. 20, Cartagena, 14 de enero de 1925.

${ }^{62}$ Artículo 60 del Código Fiscal, 1919. A.H.C., El Porvenir, Cartagena, 3 de octubre de 1921; Leal, Claudia. "La compañía minera Chocó Pacifico y el auge del platino en Colombia 1897-1930”, en Revista Historia crítica, núm. Extra 1, Universidad de los Andes, Bogotá, 2009, pp. 150-164.

${ }^{63}$ B.N.C., "Decreto legislativo No 12 de la ley 19 de 1904", en Informes y decretos, exposición de motivos y proyecto de lei sobre inmigración, 1919, p. 26.
} 
gravísimos peligros para la integridad nacional. Cumplo con el deber de manifestarlo" ${ }^{\circ 4}$. En el año de 1911, el Intendente del Chocó, en un comunicado enviado al Prefecto de la mencionada intendencia, resumió en los siguientes términos las irregularidades que se estaban presentando en el proceso de adjudicación de minas:

Escribe el Intendente al prefecto de la intendencia para denunciar ante él las irregularidades que se cometen al dar posesión de minas a todos los individuos que lo solicitan, sin estimar que estas están en terrenos destinados para la agricultura, violándose el derecho de propiedad. Se pide que no se den posesiones en terrenos no apropiados para la minería, porque en la mayoría de los casos solo se trata de adquirir la propiedad de terrenos destinados para la agricultura, y en lugar de comprarlos o denunciarlos como baldíos, se apela al medio más expedito de adquirir propiedad [...] procedimiento al cual no pueden sustraerse los primeros propietarios. Lo que se quiere evitar abusos y amparar las propiedades de numerosos cultivadores pequeños, que a menudo son víctimas de atropello y despojos violentos ${ }^{65}$.

Algunos de los inmigrantes sirio-libaneses no escaparon a este tipo de comportamientos. Precisamente, un año antes de la citada comunicación del Intendente del Chocó, un grupo de reconocidos empresarios de Quibdó enviaron un telegrama al Ministerio de Obras Públicas, donde denunciaban que los Meluk estaban violando lo establecido por el gobierno en la Ley 19 de 1904, que limitaba el número de hectáreas de tierras que podían ser denunciadas. Así lo hicieron constar Cicerón Ángel, Gonzalo Zúñiga, Jorge Díaz, entre otros, en el comunicado radicado en el mencionado ministerio:

\begin{abstract}
Ponemos en conocimiento al gobierno, que extranjeros Meluk, en su propio nombre o por medio de testaferros avisa y denuncia más (100) cien minas en este territorio, contraviniendo el Artículo 11 de la Ley 19 de 1904, además del denuncio de terrenos de minas como baldíos. Grave perjuicio para la integridad nacional $^{66}$.
\end{abstract}

Y en el mismo año en que fue expedida esta Ley, el jefe de operaciones militares del Chocó, Rafael Díaz, denunció a Luís Malluk “[...] por confabularse con otros "turcos" de Cartagena y Quibdó para apoderarse de regiones chocoanas mediante el denuncio de minas, atentando contra la soberanía nacional" ${ }^{\prime 67}$. Al parecer esta era una práctica recurrente de los Meluk, pues, así como en el caso de las minas, también miembros de esta familia se enfrentaron con las autoridades del municipio de Quibdó. En esta oportunidad, en el año de 1927 la firma comercial A\&T Meluk, levantó una edificación sobre predios municipales, querella que llegó a las instancias judiciales ${ }^{68}$.

\footnotetext{
${ }^{64}$ A.G.N., "Baldíos", tomo 32, Istmina, 23 de septiembre de 1909, p. 405.

${ }^{65}$ B.N.C. "Circular No 43”, Gaceta de la intendencia del Chocó, Quibdó, octubre 16 de 1911.

${ }^{66}$ A.G.N. "Baldíos", tomo 33, Quibdó, octubre 6 de 1910, p. 551.

${ }^{67}$ González, Luis F, "Sirio-libaneses en el Chocó”, Op Cit, p. 92.

${ }^{68}$ B.N.C., $A B C$, Quibdó, 25 de febrero de 1927, p. 1.
} 
Desde el Departamento de Bolívar, tanto los ciudadanos como las autoridades, también denunciaron las irregularidades que varios comerciantes y empresarios sirio-libaneses estaban cometiendo al apropiarse de terrenos de la nación, que en algunos casos ya estaban siendo ocupados por colonos con muchos años de anterioridad. Haciendo referencia a esta problemática, en el año de 1909, aparece una carta publicada en el periódico cartagenero el Penitente. Bajo el título de "Alarmante", que sintetiza el tono de la misiva, Pedro Ignacio Armar se dirige al gobernador del Departamento de Bolívar, exigiéndole que tome un verdadero control y regulación de la adjudicación de los terrenos baldíos en la provincia del departamento. Armar aseguraba que se estaban presentando irregularidades alarmantes, consistente en que en la zona limítrofe con Panamá existía un litoral de siete leguas de extensión donde los extranjeros sirios Abuchar Hermanos, en connivencia con otros extranjeros, están separando tierras y explotándolas. Esta firma argumentaba que ellos habían iniciado un proceso de adjudicación que, según Armar, no existía; en realidad estos señores - decía- estaban usufructuando y monopolizando la explotación de un riquísimo bien de la Nación. Al respecto, Armar señala:

[...] los terrenos que los señores Abuchar Hermanos están habitando y que pretenden se les adjudique como baldíos, están ubicados en la región conocida como "La playona", terrenos riquísimos en maderas de construcción, de fertilidad para toda clase de trabajos agrícolas, con abundantes vertientes de agua dulce y con una coquera constante de siete mil (7.000) árboles $[\ldots]^{69}$.

Armar le sumó a su denuncia un hecho de gran importancia en lo referente al control del Estado sobre esta práctica ilegal, y eran las precarias posibilidades que tenían las comunidades para hacer estos hechos públicos y denunciarlos, en gran parte, por la actitud que asumían los organismos reguladores del estado. En este caso, señala el autor:

[...] nos vimos en la necesidad de hacer esta digresión en este órgano de circulación pública por que las autoridades se parcializan con la pretensión de los señores "Abuchar Hermanos", no aceptando ni dejando constancia de la oposición que han hecho los cultivadores y vecinos de la zona a la posesión que han hecho los Abuchar de los baldíos ${ }^{70}$.

En el año de 1921, varios vecinos del distrito de Majagual (Bolívar) también protestaron por los abusos que estaba cometiendo el sirio Tafur Guerrero. A través de un comunicado, enviado al departamento de baldíos del Ministerio de Agricultura y Comercio, exigían que controlaran las acciones del señor Guerrero, a quien señalaban de pretender despojarlos de los terrenos adyacentes a la ciénaga de garrapata, donde ellos tenían cultivos desde hace más de 30 años $^{71}$.

\footnotetext{
${ }^{69}$ A.H.C., Penitente, Cartagena, 28 de noviembre de 1909.

${ }^{70}$ Ibid. Finalmente, el gobierno nacional le adjudica 2,531 hectáreas de terrenos de La Playona a la firma A\&T Meluk, en el año de 1920. A.H.C., Notaria primera, escritura pública núm. 752, Cartagena, 15 de diciembre de 1920.

${ }^{71}$ A.G.N., "Baldíos", Tomo 48, Cartagena, 20 de marzo de 1921, p. 520.
} 
Además de enfrentar las denuncias de particulares y comunidades por acaparamiento de terrenos no baldíos, como se puede observar en varias de los comunicados, los siriolibaneses también fueron denunciados por autoridades municipales del departamento de Bolívar por la misma práctica ilegal. En 1915, el alcalde de la población de San Jacinto Bolívar, envió al Ministerio de Obras Públicas, una carta que presentó ante el gobernador del departamento de Bolívar, en la que le hizo conocer el enfrentamiento que ha tenido con los señores Henrique De la Espriella y Amin Meluk, quienes han denunciado como baldíos una posesión de terreno de 1.600 hectáreas que pertenecían al municipio que él gobernaba.

En su condición de autoridad, el alcalde explicó que ya con anterioridad señor Henrique Escobar, uno de los socios de los Meluk, había ocupado una parte considerable de terrenos del municipio, con el pretexto de que estos correspondían al resguardo de una hacienda que poseía dicho señor en el punto llamado "Honduras"72, y ante el enfrentamiento de las autoridades desistió de su propósito. Pero un año después, intentó nuevamente, en asocio con los mencionados señores De la Espriella y Meluk, darle a dichos terrenos el carácter de baldíos. Lo importante de esta noticia no es solo la manifestación que hace el alcalde de que los terrenos pertenecían al municipio y por lo tanto no eran baldíos, sino que en la demarcación que hacen de los terrenos baldíos estaban de por medio trece (13) caseríos de una población de más de dos mil (2.000) habitantes, que estaban bajo la jurisdicción del municipio desde hacía más de cincuenta (50) años a la fecha. Y mucho más importante, al igual que en el caso denunciado por el señor Armar, el alcalde hablaba de las debilidades de las autoridades correspondientes ante estos casos, señalando que "[...] a pesar de lo expuesto, los señores, válidos de sus influencias personales y por su posición monetaria, tratan de atropellar e inquietar a los actuales cultivadores, sin que se haya hecho nada para impedirlo"73.

\section{Conclusión}

Todo intento de análisis del impacto de los inmigrantes sirio libaneses a la vida económica del circuito comercial que conformaban Cartagena, Quibdó, Lorica y Cereté debe reconocer que estos inmigrantes, presentes en la realidad económica de este circuito comercial en los años de 1880 y 1930, hicieron uso de diferentes mecanismos de articulación que pendularon entre las actividades económicas licitas e ilícitas, características de los mismos contextos. Estas condiciones les permitieron insertarse de forma rápida a las dinámicas comerciales de estas localidades, y les facilitaron, de alguna manera, identificar los sectores productivos más propicios para su inversión, y con ello avanzar en su proceso de posicionamiento socio-económico en el Atrato y la región Caribe colombiana. La falsificación de monedas, el contrabando y el acaparamiento de tierras fueron algunas de las prácticas ilícitas en las que incurrieron algunos de los inmigrantes sirio-libaneses. El estudio de estas dinámicas, al tiempo

\footnotetext{
${ }^{72}$ En la Compañía Agrícola Honduras, ubicada en el Departamento de Bolívar, participaban Enrique Escobar, Dadley Mac Dougal, Enrique Lecompte y los sirio-libaneses Abuchar y Malluk. A.H.C., Notaria primera, escritura pública núm. 742, Cartagena, 11 de diciembre de 1920.

73 A.G.N., "Baldíos", Tomo 38, Cartagena, 8 de diciembre de 1915, p. 25.
} 
que muestran la fragilidad de las instituciones estatales y provinciales para ejercer un monopolio fiscal, nos permite repensar la trayectoria de la exitosa articulación económica de los mencionados inmigrantes en Colombia.

\section{Fuentes}

\section{Fuente Primaria}

\section{Archivos}

Sección Republica, Fondo Baldíos-A.G.N

\section{Prensa}

Prensa oficial y comercial de Quibdó. B.N.C.

Prensa oficial y comercial de Cartagena, Lorica y Cereté. A.H.C.

Prensa comercial de Lorica y Cereté. C.D.B.R.M.

\section{Fuente secundaria}

\section{Libros}

Abad, Gustavo. Cereté su historia y cultura. Cereté, 1997.

Alzate, Alberto y Brunal, Berta. Tenencia y Concentración de la tierra en Córdoba. Montería: ed. Fundación del Caribe, 1982.

Cuesta, Marco T. El Chocó ayer, hoy y mañana. Bogotá: Colección Fundación, publicaciones consignas, 1986.

Cotes, Eduardo. Diario del alto San Juan y del Atrato. Bogotá: Colección literaria 35, fundación Simón y Lola Guberek, 1990.

Fals Borda, Orlando. Historia Doble de la Costa, tomo IV. Bogotá: Ancora Editores, 2000.

Laurent, Muriel. Contrabando en Colombia en el siglo XIX, prácticas y discursos de resistencia y reproducción. Bogotá: Universidad de los Andes-CESO, Departamento de Historia, 2008. 
Le Grand, Catherine. Colonización y protesta campesina de Colombia 1830-1950. Bogotá: Universidad Nacional de Colombia, 1998.

Solano, Sergio. Puerto sociedad y conflicto en el Caribe colombiano 1850-1930. Bogotá: Ministerio de Cultura-Observatorio del Caribe colombiano-Universidad de Cartagena, 2003.

Velázquez, Rogerio. Fragmentos de historia, etnografía y narraciones del pacifico colombiano negro. Bogotá: Instituto de Patrimonio y Cultura, 2000.

\section{Capítulos de libro}

Múnera, Alfonso, "Ilegalidad y frontera 1770-1800", en Meisel, A. (ed), Historia económica y social del Caribe colombiano. Barranquilla: Universidad del NorteEcoe, 1994.

\section{Artículos de revista}

Chávez, Matías Rodrigo y Sourrouille, Marcos. "Redes sociales y territorialidad bolichera de sirios y libaneses en el sudeste de Rio Negro, Argentina (1900-1950)", en Anuario de Historia Regional y de las Fronteras, vol. XXI, núm. 1, enero- julio 2016, pp. 159-182.

González, Luis F. "Sirio-libaneses en el Chocó, cien años de presencia económica y cultural", en Boletín Cultural y Bibliográfico, vol. XXXIV, núm. 44, Banco de la República, Bogotá, 1997.

Leal, Claudia. "La compañía minera Chocó Pacifico y el auge del platino en Colombia 1897-1930", en Revista Historia crítica, núm. Extra 1, Universidad de los Andes, Bogotá, 2009.

Rhenals Doria, Ana Milena y Flórez, Francisco Javier. "Distintos sujetos bajo un mismo predicado: Reflexión historiográfica sobre la historia empresarial en el Caribe colombiano", en El taller de la Historia, núm. 1, Revista del Programa de Historia, Universidad de Cartagena, Cartagena, 2009.

Tovar, Hermes. "Los baldíos y el problema agrario en la costa Caribe de Colombia (1830-1900)", en Revista Fronteras, núm. 1, Centro de Investigaciones de historia colonial, Instituto de Cultura Hispánica, Bogotá, 1997.

Viloria, Joaquín. "Lorica, una colonia árabe a orillas del Río Sinú”, en Cuadernos de Historia Económica y Empresarial, núm. 10, Banco de la República (CEER), Cartagena, 2003. 
Inmigrantes sirio-libaneses y sus prácticas económicas (ilegales) en Colombia, 1880-1930

\section{Tesis}

Rhenals Doria, Ana Milena. Del ideal europeo a la realidad árabe: Inmigrantes siriolibaneses en el circuito comercial entre Cartagena, el Sinú y el Atrato, (Colombia) 1880-1930, (tesis doctoral), Universidad Pablo De Olavide, 2013.

\section{Publicaciones en Internet}

Lopera, Jaime. "La colonización del Quindío", en capitulo X: la fundación de Armenia, http://www.calarca.net/libro/index10.html 2010. 